\title{
EDITORIAL
}

\section{Taxing the Digital Economy Post-BEPS, Seriously}

Adaptability to change is key to the survival of all species, ${ }^{1}$ and one could hardly identify a more dramatic change than the digital revolution we all face at the present. The international tax regime has however struggled to adapt to this transformation of the global economy, mainly because it had been designed for a long gone, pure bricks-and-mortar economy, one that has begun to change almost from the very beginning of the regime itself. With intangibles becoming more important in cross-border trade, the traditional rules started to struggle, a struggle that evolved into a crisis with the advent of true digital transactions, those in which 'Signals, in effect, are selling signals, ${ }^{2}$ as so well-articulated by Charles Kingson, who wrote one of the first, and still one of the most thoughtful scholarly articles on the taxation of digital transactions. Kingson identified the difficulties involved with international tax law reform yet concluded that such reform would be inevitable due to the incompatibility between the international tax regime and the digital economy. ${ }^{3}$

The path to reform has, however, been treacherous. At the present, more than two decades after the publication of Kingson's lecture, all seem to still struggle with the same issues. This issue of Intertax is dedicated to this struggle and the scholarly work taken to support reform of the international tax regime to adapt its rules to the digital reality. This issue, and the conference, organized by Professor Ana Paula Dourado (our Editor-in-Chief) at the University of Lisbon, which it tracks, could not have come out in a more opportune time. This Editorial is written in a week when the OECD (in the context of its so-called inclusive framework) published its interim report on Tax Challenges Arising from Digitalisation, ${ }^{4}$ and the EU forthcoming action on the taxation of the digital economy leaked to the press and expected to be imminently published. ${ }^{5}$ The OECD report manifested the lack of consensus among countries over both the need for reform and the most appropriate form such reform should take if agreed upon. The EU took a firm position that reform is inevitable, yet it stopped short of finalizing its response to the challenge. The EU strongly signalled that it is heading towards a nexus-based reform, it would still need to work on the details of such reform and in the meanwhile it would implement, via a directive, a so-called interim measure in the form of an equalization levy, a low rate turnover tax on certain particular activities of large multinational enterprises (MNE).

These divergent responses of the OECD and the EU demonstrate the disparity of policy approaches among stakeholders in the debate. Such disparity typified the debate in the last decades. Naturally, a strong contingency resisted, and still resists any reform. The most powerful stakeholders, led by the most developed world economies, naturally resist reform in times where they control the discourse and the agenda, yet beyond this reflexive conservatism such stakeholders understood that reform would entail loss of their specific controlling dominance of the international tax regime, dominance that allowed them to stack the odds in their favour in revenue terms. ${ }^{6}$ Geopolitical changes, most notably the decline of the superpowers and the ascent of emerging economies led by the BRICS countries, brought with them demand for

\section{Notes}

The exact quote: 'It is not the strongest of the species that survives, nor the most intelligent that survives. It is the one that is most adaptable to change' is often attributed to Charles Darwin.

Charles I. Kingson, The David Tillinghast Lecture: Taxing the Future, 51 Tax L. Rev.641 (1996).

Id.

See OECD, Tax Challenges Arising from Digitalisation - Interim Report 2018, http://www.oecd.org/tax/beps/tax-challenges-arising-from-digitalisation-interim-report9789264293083 -en.htm. The final report is expected in 2020.

See e.g. Anna Burchner \& Richard Taylor, Leaked Document Reveals EU Proposals for Taxing the Digital Economy (CMS Now, 7 Mar. 2018), http://www.cms-lawnow.com/ealerts/ 2018/03/leaked-document-reveals-eu-proposals-for-taxing-the-digital-economy?cc_lang=en.

6 Through e.g. their control of the OECD, the self-appointed caretaker of the international tax regime, and through the rhetoric supporting the superiority of residence-based taxation embedded particularly in the OECD Model. 
reform of the international tax rules in favour of a fairer division of tax revenues that would increase the taxing rights of source or market economies, where consumers reside, inevitably at the expense of the traditional powerful economies, in which most of the world capital and MNE reside. The demand for reform goes beyond the digital economy, yet it coincided with its ascent and had been most clearly demonstrated in its context. The digital economy permits MNE (usually resident in a developed country) to fully operate in developing countries, taking advantage of their markets without physical presence and hence without sufficient taxable presence, while such an outcome would be much more difficult and costly to devise in most old economy contexts.

The controversy extends however beyond politics and revenue grab. At the present, even serious scholars still question the wisdom of reform, advocating alternatively the more traditional avenue of tweaking the traditional rules and apply them by analogy to the new economy and digital transactions. ${ }^{7}$ This conservative approach cannot prevail. Globalization at the turn of the millennium altered business in now well-known (and profound) manners that could not be seamlessly tackled by current, acceptable norms. Remote, cross-border business has been reformulated repeatedly throughout the twentieth century (and on to the twenty-first). From radio waves to satellite-remitted content, from distant catalogue sales to electronic commerce and cloud computing, the fundamental physical presence requirement for tax jurisdiction has become increasingly anachronistic. The instinctive response to these challenges, a revision of the rules in adaptation to the new business environment by tweaking of their application based on the principles of which these rules have been derived, simply failed. These rules all relied on physical presence to legitimize and enforce taxation, so when physical presence does not exist it is presumed by use of analogy, proxies and mere legal fictions in order to secure the stability of the international tax regime, and more specifically its permanent establishment (PE) articulation, since it is believed to represent a fair and legitimate compromise between competing (usually articulated as source and residence) claims for tax jurisdiction. Pursuant to this compromise a source country may only tax a foreign person if such person participates to a significant extent in its economy - and only to the extent of such participation - with PE-type physical presence being the primary standard for such sufficient participation. Once business practices began to challenge this basic standard, using sales catalogues, for example, replacing on-the-ground sales persons or (later) computer servers performing the same functions the fairness of the compromise came into question; foreign business participated significantly in economies with no physical presence to trigger source taxation. Countries have tried to 'massage' the physical presence rules and include things beyond flesh-and-blood and brick-and-mortar as satisfying the standard for taxation, yet business progress outpaced these legal tweaks that have been proven insufficient. Income generated by the digital economy increasingly escapes taxation, especially at source. ${ }^{8}$ This failure afflicted not only the developing countries that are normally associated with 'source jurisdictions', but also productive 9 developed and emerging economies - typical 'residence jurisdictions' - as is reflected in the actions of the EU and generally all the base erosion and profit shifting (BEPS) stakeholders; BEPS is a problem to all countries and not a phenomenon solely describing redistribution from the poor to the rich countries.

This outcome presents two, distinguishable, difficulties: under-taxation at source and under-taxation overall. The former is not so obviously a problem. Viewed narrowly from the perspective of the current norms governing the international tax regime, source taxation is not warranted in most cases of the digital economy since its principal participation in the source economy is supplying goods and services to local customers, and such participation is not sufficient to constitute source tax jurisdiction. Yet, source countries now claim that the mere volume and importance of the digital economy and the flexibility of its business models increasingly permit operation in a manner that avoids source taxation, replacing traditional business formats that would have been subject to such taxation. This claim may take two slightly different forms: it may be a claim by a developing, including emerging, economy that such development is unfair since it accelerates the wealth transfer from developing to developed countries; the claim may also be that such development has so fundamentally altered the global economy that it left the current compromise (based on physical presence) inappropriate as it is no longer viewed as a fair and legitimate balance between source and residence taxation. To demonstrate these claims these countries and others involved in the debate mention the use of customer data within the source countries with no revenue compensation. This mention is just one form in which MNE may be described to remotely participate in the source economies, yet it became very prominent in the debate because it seemed new in its nature and easily demonstrable for the public and for politicians. Regardless, the bottom line is that the so-called source

\section{Notes}

7 See e.g. Maarten F. de Wilde, Comparing Tax Policy Responses for the Digitalising Economy: Fold or All-In, in this issue. And Wolfgang Schön, Ten Questions About Why and How to Tax the Digitalized Economy, 72(4/5) Bull. Int'l Tax'n 3 (2018).

8 Hence the BEPS project and it first action item, dedicated to the challenges presented by the digital economy.

9 This editorial uses the term productive colloquially to describe non-haven jurisdictions without resort to specific definitions of the term. 
jurisdictions wish to amend the current regime to accommodate 'more' source taxation, particularly of income generated by the digital economy - based on both theoretical and political grounds.

Low effective taxation of the digital economy is more generally acknowledged as a problem for the international tax regime as it harms all of the productive countries, including the most developed ones. It is clear that the digital economy's escaping taxation as stateless income ${ }^{10}$ or in so-called double non-taxation is not acceptable for all of the regime's stakeholders. The world's productive countries all face this problem together as has been apparent in their joining forces in the BEPS project, which had under-taxation of MNE as its primary target, but also dealt with the requirement for more taxation at source to stabilize a new consensus or deal to preserve the international tax regime. The BEPS Project has decided to take a conservative yet evolutionary approach, working towards increasing source taxation, yet keeping the fundamental structure of the international tax regime intact, including the reliance on the residence versus source paradigm, a balancing PE-style threshold for business taxation (at source) and consequently the retention of the source concept. Nonetheless, and despite the attention, including a political mandate, given to the project, and the ample contributions from industry and academe to a better understanding of the issues involved, the BEPS project could not deliver a solution or even a set of concrete recommendations for reformulation of the tax regime applicable to the digital economy. The project's final report just explained the issues raised, and floated three types of solutions for future discussion: a digital PE solution that would reformulate the PE concept to include digital rather than physical presence in a source jurisdiction, a withholding regime, such as the one proposed by the authors of this article, which would minimally depart from the current regime to secure sufficient source taxation and significantly reduce base erosion at source, and an equalization tax that would similarly shift some taxation to source jurisdictions. ${ }^{11}$ The inability of the BEPS project to deliver a standard solution resulted in a variety of responses by stakeholders, most of which chose to move unilaterally to secure their tax bases regardless of the impact of such moves on other jurisdictions, ${ }^{12}$ responses diametrically opposite to the core principle of the BEPS project to encourage coordination of tax policies for the common good.
The 2018 interim report leaves us in the very same place, although it includes much progress in the understanding of the challenges presented by the digital economy and the technical implementation by collective action of a standard solution. For now, it seems, conservatism has won. Yet, this is a false impression. Inaction is not a choice but rather a consequence of the competitive nature of the international tax regime that became only more so, more fractious post-BEPS. The unilateral measures, even when tagged as interim measures, taken by some countries threaten our already fragile international tax regime that seems to deteriorate towards less rather than more coordination of tax policies. Take, for example, the apparent decision of the EU to promote an equalization tax designed to target primarily United States MNE at a time when the political relationships between the United States and the EU are challenged. It gives one an impression of a political (retaliatory) rather than a technically sound move. There are many good reasons not to support an equalization tax, ${ }^{13}$ but the main fault of such a tax is that it avoids the core problem, being external to the income tax system that is at the heart of the debate, and hence cannot be seriously viewed as a solution, perhaps only a political pacifier of an arbitrary set of countries.

One may counter that while consensus is being built interim solutions may be positive to make sure that the debate continues towards a consensus type solution. Such a counter may seem consistent with the urgency to address the said challenges, expressed by this author as well as many others, yet, a more careful analysis must lead to the conclusion that inappropriate interim measures, such as the equalization tax, are necessarily undesirable, and cannot be supported since they do not bring us closer to a solution. Beyond the legal problems presented by the equalization $\operatorname{tax}^{14}$ that would serve solely as distractions from a consensus building effort, such a measure can strategically only harm that effort. Countries able to quickly legislate had already enacted their interim measures with blunt disregard of the consensus building efforts related to the taxation of the digital economy, including during the BEPS project. Most chose to skirt the problem of treaty violations by using a variety of measures allegedly outside the corporate income tax regime. Retroactive acceptance of such measures simply incentivizes other countries to further defect and act unilaterally, which cannot help coordination and consensus building. Moreover, it relieves the pressure to cooperate as

\section{Notes}

10 See Edward D. Kleinbard, Stateless Income, 11 Fla. Tax Rev. 699 (2011).

11 See OECD, Addressing the Tax Challenges of the Digital Economy, Action 1 - 2015 Final Report, OECD/G20 Base Erosion and Profit Shifting Project (OECD 2015), http://dx. doi.org/10.1787/9789264241046-en.

12 See e.g. OECD, supra n. 4.

13 See e.g. Pasquale Pistone \& Yariv Brauner, Adapting Current International Taxation to New Business Models: Two Proposals for the European Union, 71 Bull. Int'l Tax 12 (2017).

14 ibid. 
countries supposedly tax the digital economy at an 'acceptable level' and hence have a lesser incentive to promote a coordinated solution. Other countries that cannot enact such measures or that do not wish to do so would be pressed to respond or retaliate in necessarily disparate ways that necessarily result in double taxation in many cases and perhaps under taxation in other cases (when responses would comprise of competition measures, such as assisting MNE to circumvent taxation in other jurisdictions). Domestic rules change outside the consensus (like that of the United States as one may argue), could further hurt coordination and consensus building, triggering further retaliation and distrust. Finally, it is very difficult to foresee, especially in the current political climate, when could the nations of the inclusive frame work, for example, reach a consensus, meaning that the so-called interim solutions might stay with us for a long time, disrupting cross-border investment.

Interim measures are not however inappropriate per se. Interim measures 'within' the system may work if carefully designed. Measures in the spirit of potential permanent solutions are preferable for at least three reasons. First, they should not disrupt investment beyond the current regime as they will be part of such regime, even if with some adjustments. Second, they should be more fairly applied by all stakeholders since current laws already conform with the current regime that would just need adjustments. Such legitimacy is necessarily more com with consensus building than the external measures such as the equalization tax. Third, such interim measures should provide stakeholders with actual evidence and experience regarding their application, information that would be relevant for a design of permanent solution. It is unfathomable why a $5 \%$ equalization tax on activities defined in a new, vague manner, should be superior to a standard, temporary $5 \%$ withholding on all base eroding payments (and not requiring definitions), or to a tax on income attributable to a virtual PE, temporarily defined, and implemented either via a withholding tax or using the current, admittedly not perfect, attribution of income rules? ${ }^{15}$ Only inability to act and cooperate lead to this reality and we must acknowledge the threat that it presents to the stability of the international tax regime.

The various contributions in this issue include a variety of perspectives focusing on the second level question of what measures should be taken to respond to the challenges of the digital economy, and this high level debate is very helpful; for it to be fruitful, however, it is critical that all stakeholders understand that inaction is not an option and that it has a potentially dire price. ${ }^{16}$

Yariv Brauner

Hugh Culverhouse Eminent Scholar Chair in Taxation $\mathcal{E}$ Professor of Law, University of Florida, Levin College of Law Email:brauner@law.ufl.edu

\section{Notes}

15 These measures were proposed in Andrés Báez Moreno \& Yariv Brauner, Witholding Taxes in the Service of BEPS Action 1: Address the Tax Challenges of the Digital Economy, 11 (IBFD White Paper 2 Feb. 2015), retrievable at the following link: https://www.ibfd.org/sites/ibfd.org/files/content/WithholdingTaxesintheServiceofBEPSAction1-white paper.pdf (accessed Mar. 5 2018), and in Peter Hongler Pasquale Pistone, Blueprints for a New PE Nexus to Tax Business Income in the Era of Digital Economy, IBFD Working Paper (2015). The paper can be freely retrieved at the following link: http://www.ibfd.org/sites/ibfd.org/files/content/pdf/Redefining_the_PE_concept-whitepaper.pdf?utm_ source $=$ white-paper\&utm_medium $=$ email\&utm_campaign $=$ WP10-03-2015\&utm_content =Redefining_the_PE_concept-whitepaper.pdf (accessed 5 Mar. 2018). For an indepth analysis of the equalization tax and the withholding solutions, see Alessandro Turina, Which 'Source Taxation' for the Digital Economy? No Straightforward Answers, in this issue.

16 Michael P. Devereux \& John Vella, Implications of Digitalization for International Corporate Tax Reform, in this issue, and a commentary on the same article by Andrés Báez Moreno (also in this issue) expand the debate to include more fundamental reform of the entire business taxation regime, effectively promoting a global destination-based cash flow tax. Such expansion should be seriously considered, yet for pragmatic purposes this editorial focused on the issues and solutions as presented by the OECD. 